\title{
EDUCACIÓN Y ÉTICA EN UNA SOCIEDAD "LÍQUIDA"
}

Guillermo Guato

Docente de la Carrera de Filosofía y Pedagogía de la Universidad Politécnica Salesiana

La educación superior se debate entre el ocaso de una sociedad "sólida" y los albores de una sociedad "líquida”. En este contexto la ética en la educación no es más que un destello de luz que titila de acuerdo a las circunstancias del constante devenir que presenta dicha sociedad; consecuentemente, la Universidad, como el espacio último donde se genera y se desarrolla la tecnología, el conocimiento académico y otros aspectos del ser humano, de una u otra manera se encuentra naufragando en el inmenso mar de la "razón instrumental", el "imperativo tecnológico" y el "conocimiento informativo", porque no se ha logrado comprender la realidad del constante cambio; en efecto, la esencia misma de ser universidad está sujeta al vaivén de las manifestaciones culturales, lo que ha llevado a un gravísimo problema: ni directivos ni docentes se encuentran en esa "sintonía de cambio social", pues todo el quehacer universitario se presenta como "espuma" que se disipa a la "orilla del mar", y directivos y docentes han quedado anclados en el tiempo. 
Por otro lado, hablar sobre esta temática resulta complejo y al mismo tiempo halagador; complejo porque es un tema que cala hondo en cada ser académico pensante, que ha llevado a una producción casi exagerada de reflexiones sobre este tema, por lo que bien podemos estar repitiendo o alineándonos con alguna propuesta en particular; sin embargo, es halagador porque es una oportunidad más para poder reflexionar y analizar sobre esta temática particular desde nuestro contexto de "ser" latinoamericano y sobre todo ecuatoriano. Con esto no se quiere decir que vamos a elaborar una propuesta (en base a nuestras manifestaciones culturales) frente al sistema capitalista imperante en nuestra región, tampoco vamos a hacer una crítica a los distintos cambios y realidades que ofrece la sociedad "líquida", en la cual ya estamos inmersos, sino intentaremos únicamente analizar el "dinamismo" que presenta la sociedad "líquida" y, como en este contexto la educación y la ética son posibles desarrollarlos; obviamente veremos cómo dichas manifestaciones de la sociedad "líquida" se reproducen "ingenuamente" en nuestra región.

Las ideas que se verterán en este artículo no son consejos con sesgos éticos, ni mucho menos sugerencias para aplicar en el ejercicio de la docencia universitaria, sino únicamente reflexiones con un profundo asombro sobre la dinámica social actual; los retos que tiene la educación en una sociedad "líquida", y la ética que, con su luz, aunque tenue, brilla aún en la existencia misma de ser universidad.

Uno de los pensadores más influyentes en la sociedad actual es Zygmunt Bauman'1, por sus certeras reflexiones cuando se trata de definir la sociedad actual. Por tanto, las reflexiones de este artículo estarán fundamentadas y guiadas a la luz de varias de sus obras, sin 
dejar de lado a otros pensadores del campo de la filosofía, pedagogía y ética, que en su momento serán referidas.

Toda transición es imperativa en la medida que una determinada sociedad se desarrolla. Bauman, frente a la actual, la muestra cómo la sociedad "líquida", al diluir los dispositivos productores de sentido de la sociedad sólida, disolviendo también la eficacia simbólica de los mismos. En esencia, la educación superior se orienta específicamente a los jóvenes y si no conocemos la realidad de éstos, la labor educativa no será eficaz. La cultura del presente urge a reinventarse de modo continuo. Esto se convierte en un gran reto para la universidad ya que la posición actual de los jóvenes como consumidores es "sin tiempo que perder", los jóvenes saben cambiar de dirección, adaptarse a circunstancias variables, detectar de inmediato los movimientos que comienzan a producirse actualizando y rectificando su propia trayectoria, pues de ello depende su supervivencia. Suelen ser escépticos respecto a las promesas y los supuestos valores que contradigan las tendencias del mundo actual. Por ello, la educación (en el sentido "sólido", como promesa de futuro) es fuertemente cuestionada y sustituida por la fórmula educación a "lo largo de la vida". Pues no está claro cómo la educación a lo largo de la vida pueda salvar la trampa de la empleabilidad puntual y precaria, pueda dar soporte a cada sujeto en sus particularidades y en sus dimensiones cultural y social (Cfr. Bauman, 2007a: 9-15). En suma, en la sociedad "líquida" vemos un joven sin forma, versátil, y sin fundamentos que avalen procesos de formación duraderos, jóvenes "camaleónicos" que fulguran de acuerdo a las circunstancias. 


\section{"El progreso con los atajos"}

Al encontrarse la juventud inmersa en una sociedad "liquida", todo su ser se vuelve moldeable y fugaz. Las necesidades sensibles y metafísicas tienen el sello de rapidez, de light disfrazado de una aparente comodidad; así por ejemplo, en el Washington Post del 2 de enero de 2001, se informaba con mucha algarabía sobre una amplia variedad de productos que habían invadido los supermercados estadounidenses durante el año anterior, descritos como productos de comida rápida que ahorran tiempo y esfuerzo y pueden consumirse instantáneamente sin complicaciones; de esta forma se genera un principio de identificación de un progreso con atajos. Labores que solían efectuarse diariamente, en general sin quejas y a menudo con placer, han llegado a considerarse y experimentarse como una pérdida desechable, aborrecible y detestable de tiempo y energía. Los jóvenes, cada vez con mayor frecuencia, consideran agobiante el esfuerzo que implica comer una manzana: demasiado trabajo arduo para las mandíbulas y los dientes y, además, una inversión de tiempo excesiva para la cantidad de placer obtenida, les desagrada tener que pelar una naranja y prefieren beber un jugo envasado. Pero los niños no se quedan a la zaga. Smucker, una fábrica de comidas rápidas, presentó no hace mucho una novedad ampliamente aclamada: han quitado la corteza a las rebanadas de pan sobre las que se unta la mantequilla de cacahuete y la jalea de frutas de los emparedados preferidos de los niños estadounidenses. Aparentemente, la innovación da respuesta a una urgente necesidad puesto que el éxito fue instantáneo. Según parece, los niños llegaron a considerar que morder el borde más duro de la rebanada de pan era un reto demasiado laborioso para sus mandíbulas (Bauman, 2007a: 20). 
$\mathrm{Al}$ igual que los jóvenes y los niños, los padres no parecen quedarse fuera de esta tendencia. El té helado es una de las bebidas favoritas de los norteamericanos. Pero, desgraciadamente, para prepararlo a la vieja usanza primero hay que hervir agua, llenar la tetera, hacer el té y luego esperar a que el preparado se enfríe. Mucho trabajo y mucho tiempo. ¿Sobrevivirían la sed y el deseo de saciarla todo el proceso? Afortunadamente, otro potentado de la industria de alimentos, Lipton, decidió calmar la impaciencia de los amantes del té helado y ofrece a los afligidos adictos unas bolsitas de té cuyo contenido es soluble en agua fría (y hasta helada). Ahora la satisfacción puede ser instantánea, como en el caso del recientemente comercializado atún instantáneo en polvo que pone fin a la "engorrosa" tarea de perder tiempo abriendo una lata. En suma, ya no es necesario posponer las necesidades; la espera solo es el recuerdo de la memoria de la sociedad "sólida". Hoy "el progreso se da con los atajos."

\section{El síndrome de la "impaciencia"}

Hablar de paciencia es hablar de otros tiempos ya transcurridos, es traer a la memoria a nuestros abuelos y quizá también a nuestros padres. La paciencia se asociaba con la seguridad de sus actividades y metas; en la sociedad "líquida" la impaciencia es el elam vital (Bergson) de todas las actividades del joven, es el daimon (Sócrates) que caracterizaba al hombre en cuanto tal y, también podríamos decir que es el timos (Platón) que evidencia lo amorfo de la juventud.

En efecto, esperar se ha convertido en una circunstancia intolerable, a nadie nos gusta perder tiempo injustificadamente. Bauman nos habla del "síndrome de la impaciencia”. En nuestros días, toda demora, dilación o 
espera se ha transformado en un estigma de inferioridad. El drama de la jerarquía del poder se representa diariamente en innumerables salas de espera en donde se pide a algunas personas (inferiores) que tomen asiento y continúen esperando hasta que otras (superiores) estén libres para recibirlo a usted ahora. El ascenso en la jerarquía social se mide por la creciente habilidad para obtener lo que uno quiere (sea lo que fuere eso que uno quiere) ahora, sin demora. Por ejemplo, en una entrevista, una joven inglesa de 18 años declaraba: "No me gustaría, al hacer un repaso de mi vida, ver que encontré un empleo y permanecí en él para siempre sólo porque era seguro. A los padres que permanecieron en sus empleos durante toda su vida; éste es el tipo de vida que debemos evitar a toda costa" 2 . Mientras tanto un panadero neoyorquino se quejaba ante la perplejidad que sentían los que estaban del bando de los padres: "No puede usted imaginar lo estúpido que me siento cuando les hablo a mis hijos de compromiso. Como es una virtud abstracta, no la ven en ninguna parte" (Sennett, 2000: 25).

Permanencia y compromiso requieren de tiempos necesarios, requieren también de una alta dosis de "paciencia", pero al parecer esas virtudes intrínsecas de la sociedad "sólida" se han diluido o se están diluyendo en la "informidad", en lo "líquido", pues cuando Benjamín Franklin dijo "el tiempo es dinero" hacía un elogio del tiempo: el tiempo es un valor, el tiempo es importante, es algo que debemos atesorar y cuidar, como hacemos con nuestro capital y nuestras inversiones. El "síndrome de la impaciencia” transmite el mensaje inverso: el tiempo es un fastidio y una faena, una contrariedad, un desaire a la libertad humana, una amenaza a los derechos humanos y no hay ninguna necesidad ni obligación de sufrir tales molestias de buen grado. El tiempo es un ladrón. Si uno acepta esperar, postergar las recompensas debidas a su 
paciencia, será despojado de las oportunidades de alegría y placer que tienen la costumbre de presentarse una sola vez y desaparecer para siempre. El paso del tiempo presagia la disminución de oportunidades que debieron cogerse y consumirse cuando se presentaron. En suma, la juventud ya no recorre los caminos donde había que luchar día a día por sus objetivos mediatos, esa lucha ha sido reemplazada por las vivencias placenteras que se diluyen al compás de la secuencialidad de las mismas.

En este contexto podemos preguntarnos: $; Y$ la educación qué? ¿Acaso no existe la tendencia a considerar la educación como un "producto" antes que como un "proceso"? Al considerarla como un producto, la educación pasa a ser una cosa que se "consigue", completa y terminada, o relativamente acabada; por ejemplo, hoy es frecuente oír que una persona le pregunte a otra: “¿dónde recibió usted su educación?", esperando la respuesta: "En tal o cual universidad". La implicación es que el graduado aprendió todo lo que necesitaba saber acerca de las técnicas y aptitudes, aspiraciones y valores de la lengua, las matemáticas y todo el conocimiento acumulado sobre las relaciones del hombre con otros hombres, así como también su deuda con el pasado, el orden natural y su relación con él: en suma, todo aquello que necesitaba saber, que se le exigía para obtener un determinado empleo es un producto y no un proceso que garantice plenamente el desarrollo de sí mismo y de la ciencia; en efecto la universidad se encuentra con un gran reto y una necesidad imperiosa de encontrar solidez en su educación en una sociedad "líquida".

\section{Retos y sociedad "líquida"}

Los retos a los que podemos enfrentarnos en la sociedad "líquida" están presentes en todos los aspectos 
que caracterizan al ser humano, son innumerables, pero por la especificidad de nuestro tema lo focalizaremos particularmente hacia la educación. De hecho, en la sociedad "sólida" el conocimiento tenía valor puesto que se esperaba que durara, así como la educación tenía valor en la medida en que ofreciera conocimiento de valor duradero. Ya fuera que se la juzgara como un episodio aislado, o bien que se la considerara una empresa de toda una vida, la educación debía encararse como la adquisición permanente que, como todas las demás posesiones, podía y debía atesorarse y conservarse para siempre. En nuestra "sociedad líquida", las posesiones duraderas, los productos que supuestamente uno compra una vez y ya no reemplazaba nunca más, han perdido su antiguo encanto. Considerados alguna vez como activos ventajosos, hoy tienden a verse como pasivos. Los que alguna vez fueron objetos de deseo se transformaron en objetos de resquemor. ¿Por qué? Porque el "mundo vital" de la juventud contemporánea, compuesto desmañadamente con porciones de sus experiencias vitales, ya no se parece a los pasadizos ordenados, sólidos y "aprendibles" de los laberintos "de ratones de laboratorio" que hace medio siglo se utilizaban para explorar los misterios de la buena adaptación a través del aprendizaje; pues hoy estamos inmersos en el "imperativo tecnológico" donde el desarrollo de las potencialidades del estudiante queda reducido específicamente al manejo de herramientas virtuales; consecuentemente se puede hablar de un "nomadismo" académico.

En el mundo de la sociedad "líquida", la solidez de las cosas, como ocurre con la solidez de los vínculos humanos, se interpreta como una amenaza; cualquier juramento de lealtad, cualquier compromiso a largo plazo (y mucho más un compromiso eterno) auguran un futuro cargado de obligaciones que (inevitablemente) restrin- 
giría la "libertad" de movimiento y reduciría la capacidad de aprovechar las nuevas y todavía desconocidas oportunidades en el momento en que (inevitablemente) se presenten. La perspectiva de cargar con una responsabilidad de por vida, se desdeña como algo repulsivo y alarmante. Esto nos trae a la memoria la "ciudad invisible" de Calvino, donde "la opulencia puede medirse, no tanto por las cosas que se fabrican, se venden y sea compran cada día; sino, antes bien, por las cosas que se tiran diariamente para dejar lugar a las nuevas" (1998: 158). La alegría de "deshacerse" de las cosas, de descartarlas, de arrojarlas al cubo de la basura, es la verdadera pasión de nuestro mundo. Con una profunda extrañeza, lo mismo podríamos afirmar sobre la educación y preguntamos: ¿por qué el "caudal de conocimientos" adquiridos durante los años pasados en el colegio o en la universidad habría de ser la excepción a esa regla universal? Pues, en el torbellino de cambios, el conocimiento se ajusta al uso instantáneo y se concibe para que se utilice una sola vez, éstos resultan mucho más atractivos y valederos para los jóvenes.

Hoy al conocimiento se lo mira como una mercancía, o por lo menos, se ha fundido en el molde de la mercancía y se incita a seguir formándose en concordancia con ese modelo. En la sociedad "sólida", para convencer a sus hijos de los beneficios del aprendizaje, los padres y madres solían decirles: "Nadie podrá nunca quitarte lo que has aprendido"; semejante consejo puede haber sido una promesa alentadora para aquellos niños a los que se les enseñaba a construir sus vidas como casas, pero lo más probable es que la juventud contemporánea lo considere una perspectiva aterradora. Hoy los compromisos tienden a ser muy mal vistos, salvo que contengan una cláusula de "hasta nuevo aviso". En suma, en la sociedad "líquida" el conocimiento no es más que un dato casual del día a día de los jóvenes. 


\section{La radicalidad del cambio}

En todas las épocas, el conocimiento fue valorado por ser una representación fiel del mundo; pero ¿qué ocurre cuando el mundo cambia de una manera que continuamente desafía la verdad del conocimiento existente y toma constantemente por sorpresa hasta a las personas "mejor informadas"? Werner Jaeger, autor de la clásica indagación de las raíces antiguas del concepto occidental de pedagogía y aprendizaje, creía que la idea de educación había nacido de un par de supuestos: el primero era la idea de que debajo del desmenuzable estrato de diversidad, de la variada y cambiante experiencia humana, se asienta la roca dura del orden inmutable en el mundo y, el segundo, que las leyes que sustentan y gobiernan la naturaleza humana son igualmente sólidas. El primer supuesto justificaba la necesidad y los beneficios de transmitir los conocimientos de los maestros a los discípulos. El segundo, imbuía a los docentes de la confianza en sí mismos, certeza necesaria para tallar la personalidad de sus alumnos, como el escultor talla el mármol, para darle la forma que, en todos los tiempos se estimaba que debía ser justa, bella y buena y, por esas mismas razones, virtuosa y noble (Jaeger, 1980: 70-75).

Estos postulados de Jaeger fueron pilares que sostenían la teoría y praxis educativa en la sociedad "sólida” (nunca fueron refutados), y la educación tuvo su desarrollo amplio y profundo consolidándose como el eje central de toda dinámica social y económica de la época, pero eso en la actualidad está en serias dificultades, pues hoy se requiere un enorme esfuerzo para sostener cualquiera de los dos supuestos y aún más para percibirlos como conceptos evidentes por sí mismos.

Por lo que no nos queda más remedio que decir, desdichados de aquellos que persisten en sus recuerdos 
cuando encuentren que las confiables sendas de ayer al poco tiempo terminarán en callejones sin salida o en arenas movedizas, o cuando descubran que las pautas de conducta convertidas en hábitos y que alguna vez contaban con garantía absoluta comiencen a provocar desastres en lugar del éxito asegurado. En tal sociedad "líquida", el aprendizaje está condenado a ser una búsqueda interminable de objetos siempre esquivos que, para colmo, tienen la desagradable y enloquecedora costumbre de evaporarse o perder su brillo en el momento en que se alcanzan.

En un mundo volátil como el de la sociedad

"líquida", en el cual casi ninguna estructura conserva su forma el tiempo suficiente como para garantizar alguna confianza y cristalizarse en una responsabilidad a largo plazo (al menos nunca se dice si habrá de cristalizarse ni cuándo, y hay muy pocas probabilidades de que alguna vez lo haga), andar es mejor que estar sentado, correr es mejor que andar y hacer surf es mejor que correr (Bauman, 2007a: 36-38).

Ante esto, el reto de la educación se hace cada vez más grande, ya que el joven se encuentra fragmentado en cuanto a su identidad, no es más que un eco de la sociedad; el joven es el fiel reflejo del antagonismo entre el "ser" y el "devenir" que protagonizaron Heráclito y Parménides, el joven es aquel que camina por los albores de un "relativismo ingenuo" perdiéndose en el encanto de la fugacidad y la impaciencia.

\section{La memoria innecesaria}

Otro elemento importante que es necesario analizar en esta temática es la memoria, para ello, partimos de lo ya mencionado y que va en contra de la esencia de todo lo que representaron el aprendizaje y la educación 
a lo largo de la mayor parte de su historia. Después de todo, el aprendizaje y la educación fueron creados a la medida de un mundo que era duradero, esperaba continuar siendo duradero y apuntaba a hacerse aún más duradero de lo que había sido hasta entonces. En semejante mundo, la memoria era un valor positivo, tanto más rico cuanto más lejos en el pasado lograra llegar y cuanto más tiempo se conservara. Hoy, una memoria tan sólidamente atrincherada parece, en muchos casos, potencialmente inhabilitante, en muchos más engañosa y, en la mayoría, inútil. Puesto que el trabajo de memorizar produce más desperdicios que productos útiles y puesto que no hay una manera confiable de decidir de antemano qué será conveniente y qué no (cuál de los productos aparentemente útiles pronto caerá en desuso y cuál de los aparentemente inútiles gozará de un súbito resurgimiento de la demanda), la posibilidad de almacenar toda la información en contenedores que se mantienen a prudente distancia del cerebro (donde la información acumulada podría tomar subrepticiamente el control de la conducta) fue una proposición oportuna y tentadora (Bauman, 2007a: 36-40).

Los jóvenes de la sociedad "líquida" quieren tener asesores que les enseñen cómo "marchar", antes que maestros que les aseguren que están recorriendo el único camino posible ya abarrotado. El culto actual a la "educación permanente" se concentra en parte en la necesidad de actualizarse cuando a las "novedades últimas" de la información profesional se refiere.

En suma, según la vívida descripción de Paúl Virilio, "el mundo actual ya no tiene ningún tipo de estabilidad, está todo el tiempo deslizándose, escurriéndose silenciosamente"3. Lo desconocido ha cambiado de posición; ha pasado del mundo, que era demasiado vasto, mis- 
terioso y salvaje", a la "galaxia nebular de la imagen". Los jóvenes comunes de la actualidad estiman mucho más amenazadores esos volúmenes gigantescos de información ávidos de atención que los pocos "misterios del universo" que quedan y que sólo son objeto de interés para un pequeño grupo de adictos a la ciencia.

La masa de conocimiento acumulado ha llegado a ser el epítome contemporáneo del desorden y el caos. En esa masa se han ido derrumbando y disolviendo progresivamente todos los mecanismos ortodoxos de ordenamiento; temas relevantes, asignación de importancia, necesidad de determinar la utilidad y autoridades que determinen el valor. La masa hace que sus contenidos parezcan uniformemente descoloridos. En efecto, en el pasado, la educación adquiría muchas formas y demostró ser capaz de ajustarse a las cambiantes circunstancias, fijándose nuevos objetivos y diseñando nuevas estrategias. Pero, repito, el cambio actual no es como los cambios del pasado. En ningún otro punto de inflexión de la historia humana los educadores debieron afrontar un desafío estrictamente comparable con el que presenta la divisoria de aguas contemporánea. Sencillamente, nunca antes hubo una situación semejante. Aún debemos aprender el arte de vivir en un mundo sobresaturado de información. Y también debemos aprender el aún más difícil arte de preparar a las próximas generaciones para vivir en semejante mundo (Bauman, 2007a: 42-46).

\section{La impenetrabilidad de la ética}

En cualquier contexto educativo en el que nos encontremos, la ética siempre se hará presente aunque tenga que adquirir "cualquier forma" con tal de no ser desplazada de la sociedad "líquida", por lo que frente a 
ésta, la ética no se define a sí misma, sino que se abre a un campo de valores, cuyas consecuencias para la investigación científica, el desarrollo humano y el desarrollo tecnológico serán:

1. La adopción de un "postulado de humildad" mediante el cual, siendo conscientes de nuestro límite, se posibilite una contribución cuidadosa y sencilla al progreso humano académico e integral.

2. El alejamiento de todo reduccionismo y la escéptica desconfianza en los propios logros, junto a una promoción intensa de la creatividad teórica y práctica.

3. Profunda apertura dialogante que permita interconectar nuestros diferentes conocimientos en un progreso solidario.

4. El pensamiento mismo, no sólo sus productos, tiene una entraña ética. La dimensión más importante de la ética del pensador consiste en aportar ideas cualificadas a ese mundo de conocimiento objetivo (Cfr. Rielo, 1990).

Consecuentemente se puede mencionar otro elemento fundamental de la vida universitaria: la ética del pensamiento como producto objetivo. Es cierto que se pueden concebir ideas erróneas, pero también es cierto que en la medida en que mayor sea la disposición minuciosa, reflexiva, desprendida, tanto menor serán los errores, y tanto menor las consecuencias humanas y sociales negativas de los mismos. Despejar mitos que son "taras estructurales" de los esquemas conceptuales es tarea del Docente Universitario, como lo es salirse de los esquemas para buscar nuevas dimensiones más humanísticas, pues 
muchas de las actividades sociales, políticas y conceptuales de diversa índole permanecen asidas a círculos viciosos que obligan a sus actores a repetir el mismo discurso y alimentar, con su ingenua bondad, la perversión del sistema. En suma, mientras los docentes se queden anquilosados, atrapados en esa gran red de la sociedad "líquida", los jóvenes sacarán gran distancia en cuanto a cosmovisión y en cuanto al mundo simbólico; más allá de la ética descriptiva, tenemos el reto de la aplicabilidad, operatividad $\mathrm{y}$ vivencia.

\section{Educación y ética, "entidades" vinculantes}

Ética y educación son entidades que en la práctica no se las puede separar, ya que toda educación implica una ética y toda ética implica una educación; normalmente los adultos se "creen poseedores" de una ética que deben enseñar o trasmitir a los hijos y a los estudiantes; pero la sociedad "líquida" poco a poco va imponiendo ciertos parámetros en los cuales los adultos dejan de ser individuos fuera de contexto, generando la necesidad de actualizarse en todas las áreas posibles con la vaga idea de "ser jóvenes". En efecto, como lo afirma Fernando Savater en su obra "La tarea del héroe" (1994) vivimos una sociedad en la que si no se es joven se está enfermo, y como los padres, una de las muchas "deficiencias" que tienen es ser más viejos que los hijos, admitir la paternidad nos compromete con el lado de "señor" que todos queremos rechazar lo más posible.

Creemos que la educación es el momento adecuado de la ética. De hecho, el propio Aristóteles, cuando escribe la Ética a Nicómaco, la concibe como algo de lo cual hay que hablar a los jóvenes, como una preparación necesaria para entrar en el mundo de la ciudadanía. Si nos 
detenemos un momento en la dinámica social, los humanos no estamos condenados a la sociedad sino condenados a vivir entre semejantes. Los semejantes son más importantes que el hecho mismo de la sociedad, y es más importante que los maestros sean semejantes a sus estudiantes, más que cualquier cosa que nos enseñen; es importante que el maestro sea un ser humano. Enseña más el maestro al educar su humanidad que al instruir cualquier otra cosa que enseñe; esto es lo que creemos que hay que introducir cuando se habla de ética. Son los principios generales los que hay que tratar de introducir, y que a partir de ellos cada quien piense lo que quiera; pero que lo piense y sea capaz de transmitir y comunicar esos conocimientos (Cfr. Savater, 1994: 35-49). Sin embargo, de lo anteriormente dicho podemos inferir que la educación y la educación ética son partes imprescindibles de cualquier formación humana. No se puede formar solamente a las personas desde el punto de vista laboral, formarles para que cumplan funciones más o menos gestoras, sin haberles formado la capacidad de convivencia y ciudadanía, que no surge naturalmente en las personas. En este mismo sentido vamos a tratar de puntualizar algunos aspectos que a toda costa se tiene que desarrollar en el campo educativo.

En primer lugar, hay que formar la capacidad de autonomía, ya que vivimos en un mundo muy complejo y no se puede crear personas que van a vivir, constantemente, dependientes de autoridades, técnicos, curanderos, etc. que los acompañen toda la vida y les digan: "No comas esto, vete por aquí, no te arriesgues"; hay que crear personas capaces de decidir por sí mismos, de iniciativa propia, de responsabilizarse para bien o para mal de lo que hacen; esto nos parece imprescindible y tiene que ser transmitido en el momento en que aún se puede transmitir. 
En segundo lugar, formar personas capaces de cooperar con los demás; capaces de generar una actitud solidaria, prestos a la acción en el momento mismo que se requiera su apoyo. Además de una autonomía y cooperación, hace falta despertar la capacidad o la vocación de participar en la vida pública. Los valores de autonomía, de cooperación y de participación son los que hay que suscitar como valores de los jóvenes estudiantes y también como los ciudadanos que se quiere; y esto recae sobre los educadores.

Por último, otra de las ideas es cómo la educación se convierte en la única forma que hay de liberar a los hombres del "destino", es la antifatalidad por excelencia, lo que se opone a que el hijo del pobre tenga que ser siempre pobre; a que el hijo del ignorante tenga que ser siempre ignorante; la educación es la lucha contra la fatalidad. Educar es educar contra el "destino", que no hace más que repetir las miserias, las esclavitudes, las tiranías, etc. Hay que educar para la esperanza, no para la desesperanza. Si se educa diciendo que el mundo es un desastre, que todos los políticos son corruptos, que el sistema es omnipotente y nunca lograremos cambiarlo, que el neoliberalismo ha secuestrado el mundo y jamás podremos enfrentarnos a sus malévolas intenciones, que todo está perdido, se creará universitarios y una sociedad de pesimistas cómodos que se dedicarán a vivir, y culparán de todos los males a cualquier cosa que tengan que soportar (Cfr. Savater, 1994: 52-59).

En suma, trascender la ética como reflexión teórica y convertirla en práctica es imprescindible. La pregunta de la ética es cómo vivir. De modo que la ética académica quedará más o menos encerrada en los círculos profesorales académicos; pero la ética práctica, seguirá siendo la esencia misma de toda acción humana, por ende la esencia misma de la relación docente y estudiante. 


\section{Educación en el "Posdeber"}

Se han dado hasta aquí algunas pistas de reflexión sobre el antagonismo evidente entre ética y educación en una sociedad "líquida", pero aún hay otros datos importantes que ayudarán a conocer y comprender a la sociedad, a la cultura universitaria, para así poder actuar "eficientemente" en una lucha que aparentemente está perdida. Esto no es pesimismo, sino intencionalidad. Se busca que las autoridades y docentes que están frente a la educación superior tomen con absoluta seriedad la realidad de esta sociedad "líquida", de lo contrario la ética es una especie de "geometría variable" donde "todo se vale", y que ahora se ha constituido en un "posdeber" que con un ímpetu insostenible hace añicos la "era del deber" de las éticas de responsabilidad y conciencia histórica, como bien lo afirma Lipovetsky.

\section{La educación actual: necesidad de trabajo conjunto}

Si los docentes quieren sobrevivir en una sociedad "liquida", deben trabajar duro, constante y en conjunto; pues de seguro no sobrevivirán si se conducen como islas sin comunicación, donde las actividades académicas naufragan solitarias al vaivén de los "caprichos líquidos", donde cada uno hace lo que puede y, no es más que un ente funcional. En efecto, el mundo se debate en luchas de poder, de valores e intereses, de propuestas políticas y económicas mientras la escuela sigue exigiéndoles a sus alumnos que no falten a clases, que hagan la tarea, que estudien los libros (depósitos de verdades) y todo ello sin relación con lo que los alumnos vivencian antes y después de ingresar al recinto escolar. Las vivencias en el sentido 
más pleno, es decir, como conjunto de experiencias que posibilitan la conformación de una visión del mundo, visión que generalmente es negada por el profesorado y en ocasiones por la institución escolar, y que es construida por el individuo desde los referentes previamente formados. "El sujeto es la voluntad de un individuo de actuar y ser reconocido como actor" (Touraine, 1993: 251), de ahí que entre profesor y alumno tenga que generarse tal reconocimiento, pues de lo contrario imposible que se asuma un compromiso, propio de un proceso educativo. La educación actual tiene delante de sí retos que son insoslayables; en tanto la formación de las nuevas generaciones requiere considerar las condiciones de existencia a las cuales nos enfrentamos todos los seres humanos, es necesario romper el mito de la educación del mañana, pues los requerimientos son actuales, pues al pensar de esa manera se profundiza la separación entre lo científico y lo humano.

Como se dijo anteriormente, el reto en la educación requiere de una acción inmediata, pero: ¿estamos preparados para esta gran tarea? ¿Vivenciamos la ética como condición necesaria para persuadir a la juventud universitaria? Y otras inquietudes más. Las respuestas a ellas no son "halagadoras"; es alarmante enterarse que los docentes tienden a actuar represivamente contra aquellos universitarios que les han evaluado mal, o bien, que justifican los resultados de su evaluación aludiendo a la "subjetividad" de los alumnos, poniendo énfasis en el sentido peyorativo del término; "me evaluaron mal porque exigí", "no son capaces de evaluar objetivamente", "no saben lo que quieren", etc. Son expresiones comunes entre los docentes en los pasillos y espacios académicos. Más preocupante aún es el hecho de referirse a los alumnos con calificativos negativos: "son unos flojos", "no quieren leer", 
"son apáticos", "nada les interesa", "no deberían estar aquî", "mejor métete un tiro”, “ándate a bañar”, etc. Pues, esas expresiones en nuestro intelecto no son más que armas letales para que la educación en la sociedad "liquida" sea efímera.

En estas circunstancias, no se debe olvidar que la educación tiene la posibilidad de crear las condiciones humanas necesarias para la constitución de sujetos activos; de no hacerlo así, se seguirá negando la participación real y activa de los estudiantes en la construcción de su propio proceso educativo, no se podrá esperar que se sientan capaces de construir paulatinamente un mundo más humano y democrático, que caracteriza a la sociedad "sólida".

\section{Últimas consideraciones}

Para finalizar la reflexión sobre la temática planteada, se recordará algunas ideas importantes que algunos filósofos y pedagogos hicieron "brillar" en su momento; por ejemplo, no hay que olvidar que, la multiplicidad de dimensiones o expresiones humanas, que se caracterizan por poseer autonomía y universalidad, pueden perfeccionarse mediante una educación integral, la misma que implica la educatividad de educadores y educabilidad de educandos en un proceso de desarrollo interactivo, continuo, crítico y creativo al considerar las dimensiones humanas en una perspectiva holística. La ética, en cuanto ciencia normativa, regula necesariamente la actividad educacional convirtiendo a la educación en la dimensión perfeccionadora de todas las otras.

Bentham y John Stuart Mill (Warburton, 2002: 172-179) promovieron un lema que en el lenguaje kantiano se traduciría, como juicios condicionales o hipotéticos: 
"Si actúo bien, obtengo un beneficio". Kant, planteó que no puede comprometerse un acto moral a consecuencias pragmáticas por muy buenas que ellas sean. A los "imperativos hipotéticos" que responden a "meros preceptos de la habilidad" antepuso los "imperativos categóricos", los que "serían leyes prácticas" (Cfr. Kant, 2000: 70-78). Un seguidor contemporáneo de este pensamiento es John Rawls; en su obra "Teoría de la Justicia" afirma la incomprometibilidad de la verdad y de la justicia sobre cualquier beneficio. Establece así, una prelación de la rectitud del acto por sobre el bien esperado de tal acto. De tal manera, que una injusticia es tolerable sólo para oponerse a una injusticia mayor y no para lograr un bien mayor (1971: 50-58). Por ende, la educación en la actualidad muchas veces se presenta configurada con esos parámetros, se encuentra con un problema permanente, en el que existen dos exigencias fundamentales: una relacionada con los conocimientos que deben ser creados, re-creados, mantenidos, acumulados y transmitidos de generación en generación; otra, la más importante porque en esencia fundamenta esta transmisión, referida al sentido de todas estas actividades educacionales y que se traduce aquí en uno de los temas tratados; en una palabra, ética, ésta exige, empero, un equilibrio en el desarrollo de la multiplicidad de estas dimensiones. Ellas se definen por la autonomía y universalidad que se manifiesta en cada una; así, la ciencia se muestra autónoma y universal desde su propia esfera.

La educación superior es un ser en relacióncon-otro, como lo afirma Heidegger; sin embargo, la individualidad de cualquier sujeto parte de seres humanos que actualizan en otros algo que los realiza también a ellos mismos; de esta forma, a la condición humana de ser-con-otro se agregan las condiciones de ser-por-otro y de ser-para-otro (Cfr. Heidegger, 1999: 155-160). Todas ellas 
actualizan la naturaleza humana y se resuelven en exigencias o responsabilidades personales y comunitarias, características propias de una sociedad "sólida".

Mientras mejor realice su condición de ser-porotro, mejor realizará la de dar o de ser-para-otro, además de la de compartir o de ser-con-otro. La educatividad docente es una forma de realizar la condición de ser-paraotro como la educabilidad discente, la de ser-por-otro. De esta forma, damos y recibimos. Es natural y necesario que padres, profesores, profesionales, científicos, filósofos $y$, en general, personas que están en una situación de dar, ofrecer y enriquecer a los demás con sus oficios, profesiones y habilidades diversas, realicen en forma natural la condición humana de ser-para-otro, dejando de lado todas esas taras que atan tanto a docentes como alumnos. Luego de estas reflexiones, quizá habrán surgido varias preguntas, quizá incluso serias objeciones con las ideas vertidas; por esa razón, posiblemente es necesario hacer algunas aclaraciones. No debemos olvidar que el pensamiento filosófico, pedagógico y ético en el plano académico tiene un origen ajeno a nuestro contexto latinoamericano y ecuatoriano, por ende, la cosmovisión sobre Dios, hombre y mundo son esencialmente diferentes a la norteamericana y europea; en este sentido, los "problemas" que presentan dichas sociedades "líquidas", no necesariamente tienen el mismo nivel de percepción en nuestro contexto, sin embargo, los "tentáculos líquidos" se extienden a todos los rincones del planeta, involucrándonos en esa "dinámica".

Recordemos también que la ética europea es "abstracta" y es operativa en esa misma dimensión; las necesidades materiales están cubiertas ciertamente, por lo que la propuesta ética viene desde esa lógica y obviamente no va a concordar con la visión latinoamericana y, por 
ende, ecuatoriana. Por estas tierras, la ética se apega más a la materialidad: las necesidades vitales que no son cubiertas. De lo dicho, implantar una ética con un carácter globalizante, en teoría es posible pero en la práctica se evidencia la diferencia.

Por último, la educación superior tiene ese formato extrínseco a nuestra realidad, es importante comprender nuestro contexto, nuestra lógica, nuestras necesidades vitales y humanas y desde allí entrar en procesos educativos contextuales y no, al contrario, asimilar formatos ajenos a nuestra realidad e querer implantarlos imperativamente, "ajustándonos a esa lógica”, que en la práctica no es procedente; debemos asumir y comprender urgentemente nuestra realidad si queremos "sobrevivir" en esta sociedad "líquida".

\section{Notas}

1 Polaco, Profesor de Filosofía y Sociología en la Universidad de Varsovia, luego en Estados Unidos, Israel y Canadá, actualmente reside en el Reino Unido. Autor de varias obras que llevan el término "líquido".

2 Entrevista por BURKMAN, O. El Guardián, 21 de marzo de 2001.

3 VIRILIO Paúl, Intervenciones Selectas, p. 40. 


\section{Bibliografía}

BAUMAN Zygmunt.

2002 La Cultura como Praxis. Buenos Aires: Paidós.

2006 Ética Posmoderna. México: Siglo XXI.

2007a Los Retos de la Educación en la Modernidad Líquida.

Barcelona: Gedisa.

2007b Vida de Consumo. México: Fondo de Cultura.

CALVINO, I.

1998 Las ciudades invisibles. Madrid: Siruela.

JAEGER, Werner

1980 Paideia. Los Ideales De La Cultura Griega. México: Fondo de cultura económica.

HEIDEGGER MARTÍN.

1999 Ser y Tiempo. México: FCE.

KANT IMMANUEL

2000

Fundamentación de la Metafísica de las Costumbres. México: Taurus.

MOUNIER, E.

1968 El Personalismo. Buenos Aires: Editorial Universitaria. RAWLS, John.

1971 Teoría de la Justicia. Cambrige, Massachusetts: The

RIELO, Fernando Belknap Press of Harvard University Press.

1990 "Concepción genética de lo que 'no es' el sujeto absoluto y fundamento metafísico de la ética". En: Raíces y valores históricos del pensamiento español. VV. AA. Sevilla: Fundación Fernando Rielo.

SAVATER, Fernando

$1994 \quad L a$ tarea del héroe. México: Destino.

1997 El Valor de Educar. México: IEESA-CEA.

SENNETT, R.

2000 La Corrosión del Carácter. Las Consecuencias Personales del Trabajo en el Nuevo Capitalismo. Barcelona:

TOURAINE, A. Anagrama.

1993 Crítica de la modernidad. Madrid: Temas de Hoy. WARBURTON Nigel.

2002 La Caverna de Platón. Barcelona: Ares y Mares. 